\title{
Making Progress in Perfusion Practices
}

DOI: $10.21470 / 1678-9741-2019-0154$

I congratulate the Journal for publishing this helpful tool to modernize perfusion practices in Brazil. Old ideas and norms that governed behaviors in the past may not be effective nowadays, therefore we cannot continue doing the same things and expect different results.

The function and performance of complex systems like Heart Centers depend on the interactions of precise technical and organizational factors. Their structure will not be resilient if perfusion - a vital component - malfunction. These systems require everyone to understand WHY they do what they do. Interestingly, every person and every organization know WHAT they do and know HOW they do it. Unfortunately, very few people or organizations know WHY they do what they do that reflects believes, reasons and objectives of an institution and determines the outcomes.

Doing things without reason can harm organizations. In medicine, many things that doctors and nurses do is because "that is the way we have always done it" - a parallel play in which each one does their things - that can hurt patients. It can be due to lack of knowledge, attitude or practices that have become automatic - ignoring WHY that would allows people to abandon pseudoscientific theories. While vanguard organizations are efficient in dealing with the problems of unpredictable systems, in those that fail, their parts come together through hard work, goodwill, and improvisation. In addition, their components are managed independently when, in fact, they are interdependent. In them, it is essential to avoid complacency - feeling satisfied with your abilities or situation and believing that you do not need to try harder.

\section{Inequality}

Despite their limited resources, some centers continue to do a good work through leadership, patience, perseverance, dedication, adaptability and creativity that comes with working under adversity. In this context, a gradual implementation of standards and guidelines should avoid false urgency, provide the opportunity to learn and improve in addition to moderate the financial burden ${ }^{[1]}$.

\section{Viewpoints:}

- An initial agreement on a problem may not result in an agreement on the solution.

- Since online publications may limit the number of readers, the PDF version should be available to those implementing the guidelines — including all coauthors.

- Implementing the recommendations will require time, work, new equipment, resources and training of those involved.

- Unit chiefs and administrators should receive a copy of the document to understand WHY it was produced and WHAT needs to be done.

\section{Rodolfo A. Neirotti ${ }^{1}$, MD, PhD, MPA, FEACTS}

(D) https://orcid.org/0000-0003-3878-1319

${ }^{1}$ Clinical Professor of Surgery and Pediatrics, Emeritus Michigan State, Brookline, MA, USA and honorary member of Sociedade Brasileira de Cirurgia Cardiovascular (Brazilian Society of Cardiovascular Surgery), São Paulo, SP, Brazil.

\section{REFERENCES}

1. Caneo LF, Matte G, Groom R, Neirotti RA, Pêgo-Fernandes PM, Mejia JAC, et al. The Brazilian society for cardiovascular surgery (SBCCV) and Brazilian society for extracorporeal circulation (SBCEC) standards and guidelines for perfusion practice. Braz J Cardiovasc Surg. 2019;34(2):23960. doi:10.21470/1678-9741-2018-0347. 